\title{
Five cases of sarcoidosis in one family: a new immunological link?
}

\author{
J Elford, P Fitch, E Kaminski, C McGavin, I P Wells
}

\begin{abstract}
We report a family in which five members have been affected with sarcoidosis. The radiological findings of all cases are presented, together with HLA typing, $T$ cell subset and cytokine analysis in four cases. A new HLA association in the presentation of sarcoidosis is suggested. (Thorax 2000;55:343-344)
\end{abstract}

Keywords: familial sarcoidosis; immunology; genetics

Whilst there are about 450 case reports of familial sarcoidosis in the literature, ${ }^{1}$ of particular interest in this report is the fact that four of the five family members we present here are blood relatives, whilst the fifth member is related only by marriage. Figure 1 shows a family tree of the affected family.

We review the current literature with respect to familial sarcoidosis and confirm previous findings of HLA B8 in association with both bilateral hilar lymphadenopathy and spontaneous resolution of disease. We also suggest an association, previously unreported, between HLA A2 and pulmonary changes in the presentation of sarcoidosis

Case 1

In 1991 this 52 year old previously fit woman presented with right sided pleuritic chest pain and a febrile respiratory illness. A chest radiograph was obtained in May 1991 and showed diffuse bilateral coarse reticular shadowing with areas of confluence in the right lower zone and the left mid zone, as well as bilateral hilar lymphadenopathy. Pulmonary function tests were normal but a Kveim test was positive. She received no further treatment and in December 1995 her spirometric tests remained normal, with the chest radiograph unchanged save for some bilateral upper lobe shrinkage.

Accepted for publication

10 September 1998

Department of

Derriford Hospital,

Department of

J Elford

Department of

E Kaminski

Correspondence to: Dr C McGavin

Received 11 December 1997 Returned to authors 2 March 1998

Revised version received

5 June 1998

Case 5 Case 4 Case 3

Figure 1 Family tree of five cases of sarcoidosis within one family.
Case 2

In December 1993 the 26 year old daughter of case 1 presented with left pleuritic chest pains, progressive dyspnoea, and occasional wheeze. Physical examination was unremarkable, but a chest radiograph at that time showed gross bilateral nodular shadowing with some areas of confluence.

A computed tomographic (CT) scan confirmed the bilateral diffuse change but also showed bilateral hilar lymphadenopathy. A transbronchial biopsy was unhelpful but a Kveim test was positive. Spirometric tests revealed a severe ventilatory defect (forced expiratory volume in one second $\left(\mathrm{FEV}_{1}\right) /$ forced vital capacity $(\mathrm{FVC})=1.64 / 1.901$, predicted $3.48 / 4.271$ ). She was prescribed prednisolone for symptomatic relief and her FVC rose to 2.41 with the chest radiograph showing considerable reduction in the nodular shadowing. Her steroids were reduced and later stopped because of side effects, following which a chest radiograph showed worsening of the pulmonary shadowing. In August 1995 azathioprine was introduced, following which there was gradual improvement in symptoms and spirometric parameters, with current $\mathrm{FEV}_{1} / \mathrm{FVC}=2.7 / 3.151$. A recent chest radiograph confirms some resolution in the pulmonary shadowing.

Case 3

In December 1993 this 31 year old nurse, married to case 4, presented with erythema nodosum. A chest radiograph at this stage showed bilateral hilar lymphadenopathy. A Kveim test was positive. She received no treatment and by February 1996 her chest radiograph had shown considerable reduction in the bilateral hilar lymphadenopathy. It is interesting to note that there is no blood relationship between this case and the others.

\section{Case 4}

In June 1995 the 32 year old brother of case 2 presented with cough and wheeze. Chest radiography revealed gross bilateral hilar and right paratracheal lymphadenopathy, as well as some linear shadowing in the right mid zone. The Kveim test was positive. He received no specific treatment. Over the following year the hilar lymphadenopathy regressed but the pulmonary shadowing worsened, becoming predominantly nodular in the right mid zone. $\mathrm{He}$ continues to receive no treatment.

Case 5

In November 1996 the older brother of cases 2 and 4 presented with chest pain and palpitations. A chest radiograph showed bilateral hilar 
Table 1 HLA typing data split into familial haplotypes, levels of $T$ cell subsets, and secretion of IL-2, IL-4, and IFN- $\gamma$ in four cases of familial sarcoidosis

\begin{tabular}{|c|c|c|c|c|}
\hline & Case 1 & Case 2 & Case 3 & Case 4 \\
\hline \multicolumn{5}{|l|}{ HLA typing } \\
\hline \multirow[t]{2}{*}{ Haplotypes } & $\begin{array}{l}\text { A2, B7, } \\
\text { DR12 }\end{array}$ & $\begin{array}{l}\text { A2, B51, } \\
\text { DR14 }\end{array}$ & $\mathrm{A} 3, \mathrm{~B} 8, \mathrm{DR} 17$ & $\mathrm{~A} 2, \mathrm{~B} 7, \mathrm{DR} 12$ \\
\hline & $\begin{array}{l}\text { A2, B51, } \\
\text { DR14 }\end{array}$ & $\begin{array}{l}\text { A32, B44, } \\
\text { DR14 }\end{array}$ & $\mathrm{A} 11, \mathrm{~B} 7, \mathrm{DR} 15$ & $\begin{array}{l}\text { A11, B7, } \\
\text { DR15 }\end{array}$ \\
\hline \multicolumn{5}{|l|}{$\mathrm{T}$ cell subsets $\left(\times 10^{9} / 1\right)$} \\
\hline CD3 (NR 1.1-1.7) & 1.01 & 0.64 & 1.05 & 0.74 \\
\hline CD4 (NR 0.7-1.1) & 0.47 & 0.44 & 0.62 & 0.29 \\
\hline CD8 (NR 0.5-0.9) & 0.58 & 0.18 & 0.36 & 0.30 \\
\hline \multicolumn{5}{|l|}{ Cytokines (pg/ml) } \\
\hline IL-2 (NR 600-1500) & 275 & 274 & - & 63 \\
\hline IL-4 (NR 0-35) & 426 & 13 & - & 4 \\
\hline IFN- $\gamma(\mathrm{NR} 1000-20000)$ & 2681 & 6000 & - & 6224 \\
\hline
\end{tabular}

$\mathrm{IL}=$ interleukin; $\mathrm{IFN}=$ interferon; $\mathrm{NR}=$ normal range.

lymphadenopathy which was subsequently confirmed by a CT scan of the thorax. A diagnosis of sarcoidosis was made without histological confirmation. He received no treatment.

\section{Results}

The four affected members of the family we report who live in south-west England have been HLA typed and the results are set out in table 1. Only one of the four cases has HLA B8 (case 3 ) and she is related to the family only by marriage. She presented with bilateral hilar lymphadenopathy and erythema nodosum, a recognised association with HLA B8 in the literature. ${ }^{2}$ In addition, her disease has largely resolved spontaneously, a finding also associated with HLA B8. ${ }^{3}$

Also of particular interest is the fact that two genetically unrelated affected family members (cases 3 and 4) share an identical haplotypenamely, A1 1, B7, DR15. It is not clear from our study what importance should be attached to this finding, but the probability of this occurring by chance is estimated at one in many thousands.

$\mathrm{T}$ cell subsets and cytokine secretion of interleukin (IL)-2, IL-4, and interferon gamma $(\mathrm{IFN}-\gamma)$ by mononuclear cells were also measured in the blood of the three genetically related affected family members living locally (table 1). The levels of all $\mathrm{T}$ cell subsets were reduced in all three patients and the production of IL-2 was also low compared with a normal population. This is consistent with the data published by Garlepp et $a l^{4}$ which showed a reduction in blood CD4+ and CD8+ cell production of IL-2. There are two possible explanations for these findings; it may be a reflection of overall $\mathrm{T}$ cell hyporesponsiveness due to sarcoidosis or, alternatively, an underlying $\mathrm{T}$ helper cell hyporesponsiveness may predispose to sarcoidosis.

\section{Discussion}

Of the cases of familial sarcoidosis published to date, it is more common in monozygotic than in dizygotic twins, in like sex pairs than in unlike sex pairs, and in mother-child relations than in father-child relations. ${ }^{56}$ Our study is unusual in that we report five cases-two mother-son relationships and one motherdaughter relationship, three siblings, and a husband-wife relationship. In all but one of the patients the diagnosis was confirmed by a positive Kveim test.

Whilst the first ever case of sarcoidosis was probably described by Boeck in $1899,{ }^{7}$ familial sarcoidosis was not described separately until 1923. ${ }^{8}$ Since then a total of nearly 450 cases has been presented worldwide. ${ }^{1}$ The prevalence of familial sarcoidosis is variable; in Ireland, where there is a high national prevalence of sarcoidosis, a study of 114 index cases showed that $9.6 \%$ of them had at least one sibling with the disease. ${ }^{9}$ A higher than average prevalence for sarcoidosis is also reported amongst West Indians, ${ }^{10}$ with familial disease occurring in $5.4 \%$ of native islanders of Martinique. ${ }^{11}$ These figures contrast sharply with reports of a prevalence of familial sarcoidosis of about $1 \%$ in Europeans. ${ }^{12}$

There are many reports in the literature of HLA associations in familial sarcoidosis, suggesting possible genetic factors in the aetiology of the disease. Of the three genetically related members in our report, HLA A2 is common to all. The fourth relative was not available for testing (case 5). In all these cases the disease involved pulmonary changes as well as giving bilateral hilar lymphadenopathy. We are unaware of any previously reported link between HLA A2 and pulmonary sarcoidosis, and we propose this as a new association. Previously published data also report that HLA DR3 confers a good prognosis ${ }^{13}$ with HLA DR5 leading to increased susceptibility for the development of the disease. ${ }^{14}$ Our results can add no weight either in favour or against either of these hypotheses.

In conclusion, our report raises the possibility of an association between HLA A2 and familial sarcoidosis with lung disease. It will be interesting to see whether further reports lend support to this.

1 Soria LM, Valverde Garcia J, Sole JM, et al. Familial sarcoidosis: a case report. Sarcoidosis 1990;7:133-5.

2 Neville E, James DG, Brewerton DA. HLA antigens and features of sarcoidosis. In: Wiliiams WJ, Davies BH, eds. Sarcoidosis. Oxford: Pergamon Press, 1983: 253.

3 Smith MJ, Turton CWG, Mitchell DN. Association of HLA B8 with spontaneous resolution in sarcoidosis. Thorax 1981;36:296-8

4 Garlepp MJ, Rose AH, Dench JE, et al. Clonal analysis of lung and blood $\mathrm{T}$ cells in patients with sarcoidosis. Thorax 1994;49:577-85.

5 Sharma OP, Neville E, Walker AN, et al. Familial sarcoidosis: a possible genetic influence. Ann NY Acad Sci 1974;278:386-400.

6 BTTA. Familial associations in sarcoidosis. Tubercle 1973; 54:87-97.

7 Boeck C. F Cutaneous Dis 1899;17:543-50.

8 Martenstein $H$. Knochveranderungen bei lupus pernio. $Z$ Haut Geschlechtskr 1923;7:308.

9 Brennan NJ, Crean P, Long JP, et al. High prevalence of familial sarcoidosis in an Irish population. Thorax 1984;39: 14-8.

10 Brett GZ. Epidemiological trends in tuberculosis and sarcoidosis in a district of London between 1958 and 1963. Tubercle 1965;46:412.

11 Turiaf J, Battesti JP, Jeanjean Y, et al. Sarcoidose familiale: 26 cas dans 12 familles. Nouv Presse Med 1978;913-5.

12 James DG, Piyasena KHG, Neville E, et al. Possible genetic influences in familial sarcoidosis. Postgrad Med $\mathcal{F} 1974 ; 50$ : $664-70$.

13 Gardner J, Kennedy HG, Hamblin A, et al. HLA associations in sarcoidosis: a study of two ethnic groups. Thorax 1984;39:19-22.

14 Nowack D, Gobel KM. Genetic aspects of sarcoidosis. Arch Intern Med 1987;147:481-3. 